\title{
Evaluating Frequency Quality of Nordic System using PMU data
}

\author{
Xu, Zhao; Østergaard, Jacob; Togeby, Mikael; Isleifsson, Fridrik Rafn
}

Published in:

Proceedings of the IEEE PES GENERAL MEETING 2008

Link to article, DOI:

10.1109/PES.2008.4596468

Publication date:

2008

Document Version

Publisher's PDF, also known as Version of record

Link back to DTU Orbit

Citation $(A P A)$ :

Xu, Z., Østergaard, J., Togeby, M., \& Isleifsson, F. R. (2008). Evaluating Frequency Quality of Nordic System using PMU data. In Proceedings of the IEEE PES GENERAL MEETING 2008 (pp. 1-5). IEEE.

https://doi.org/10.1109/PES.2008.4596468

\section{General rights}

Copyright and moral rights for the publications made accessible in the public portal are retained by the authors and/or other copyright owners and it is a condition of accessing publications that users recognise and abide by the legal requirements associated with these rights.

- Users may download and print one copy of any publication from the public portal for the purpose of private study or research.

- You may not further distribute the material or use it for any profit-making activity or commercial gain

- You may freely distribute the URL identifying the publication in the public portal 


\title{
Evaluating Frequency Quality of Nordic System using PMU data
}

\author{
Zhao Xu, Member, IEEE, Jacob Østergaard, Member IEEE, Mikael Togeby, Fridrik Rafn Isleifsson
}

\begin{abstract}
This paper focuses on analysing frequency quality of Nordic power system using measurements from Phasor Measurement Units (PMU). The PMU data of one year long period is used which has very high time resolution $(20 \mathrm{~ms}$ per sample) and is able to provide detailed information in evaluating frequency quality and its correlation with time. The results show that the frequency quality of the Nordic power system is not satisfactory according to the suggested requirements. The electricity market operation is found to be one of the major reasons behind. Based on the results, discussion of frequency control for future power system is made where several new technologies of interests are suggested to be investigated.
\end{abstract}

Index Terms - Frequency quality, Phasor Measurement Unit, demand as frequency controlled reserve

\section{INTRODUCTION}

Maintaining frequency stability is first of all important for a stable operation of the power system, and to reduce the risk for blackout. This is because stable frequency is important to ensure constancy of speed of induction and synchronous motor loads in power systems. Constant speed of such loads is particularly important for their satisfactory performance for many industrial applications in such as power production [1] and many manufactories e.g. semiconductor fabrication. Stable frequency is also important for equipment that uses power frequency as time reference. In addition, reactive components of equipment are also affected by frequency variations.

Fundamentally, power system frequency reflects the balance between electricity generation and demand. If a system experiences a lack of supply, the frequency will decrease from the nominal value, which is $50 \mathrm{~Hz}$ for Nordic system and $60 \mathrm{~Hz}$ for North America respectively; if a system experiences a lack of demand, the system frequency will rise accordingly. A variety of measures are utilized for frequency control in power system operation. First of all, the scheduling of generation according to demand can be

This work was supported by the Danish Public Service Obligation (PSO) research funding program, Project "Demand as Frequency Controlled Reserve", Grant no. 2005-2-6380.

Zhao $\mathrm{Xu}$ is an Assistant Professor with Centre for Electric Technology, Ørsted•DTU, Technical University of Denmark, DK-2800 Lyngby, Denmark (e-mail: zx@oersted.dtu.dk)

Jacob Østergaard is Centre Head and Professor with Centre for Electric Technology, Ørsted•DTU, Technical University of Denmark, DK-2800 Lyngby, Denmark (e-mail: joe@oersted.dtu.dk)

Mikael Togeby is Partner and Senior Consultant with Ea Energianalyse A/S, Frederiksholm Kanal 1, 1220 Copenhagen, Denmark (e-mail: mt@eaea.dk)

Fridrik Rafn Isleifsson is an research assistant with Centre for Electric Technology, Ørsted•DTU, Technical University of Denmark, DK-2800 Lyngby, Denmark (e-mail: fri@oersted.dtu.dk) done through either the centralized dispatching or electricity market. Secondly, automatic and manual reserved are utilized in case of disturbances. The reserves are also differentiated in the frequency threshold and time frame for activation, e.g. the frequency controlled normal reserve is to be competently activated within 2-3 minutes, when frequency reaches $49.90 / 50.10 \mathrm{~Hz}$ in the Nordic system [2].

Due to the high importance, power systems in practice usually have strict requirements for frequency quality. E.g. in Nordic system, the normal range of frequency is set between 49.90 to $50.10 \mathrm{~Hz}$. The operation target is to maintain the frequency within this range for most of time, and system operation outside the range should be limited to no more than about 1200 minutes per year [3]. In order to examine if the requirement is satisfied in practical operation of Nordic system, measurement data from PMUs with fairly high time resolution has been analysed in this paper. The results indicate that the actual frequency quality deviates from the suggested requirement. In addition, the reasons underlying have been analysed due to the current electricity market design and etc. Furthermore, the measures for improving the frequency control have been discussed in the context of increased penetration of fluctuating renewable energy in the future.

\section{DAta ACQUisition From Phasor MeAsurement Units}

\section{A. DTU PMUs in the Nordic power system}

The frequency data in this paper are measured by PMUs which are developed at Centre for Electric Technology (CET), Technical University of Denmark (DTU) [4, 5]. These PMUs are installed in the Eastern Danish power system, which is part of the Nordic system (The Nordic power system consists of Eastern Denmark, Norway, Sweden and Finland). The substation names and the (lineline) voltage levels where the PMUs are installed are listed below,

- Hovegård, $400 \mathrm{kV}$

- Hovegård, $132 \mathrm{kV}$

- Asnæsværket, 400 kV

- Radsted, $132 \mathrm{kV}$

Fig. 1 shows the locations of these PMUs installed in Eastern Denmark. One additional PMU is installed at the laboratory of CET, DTU which has a nominal voltage of $400 \mathrm{~V}$, and another two PMUs are installed at the connection point of two generators in the distribution system at Bornholm island (not shown in Fig. 1).

The PMUs conduct measurement of frequency and other quantities e.g. voltage and angle at $20 \mathrm{~ms}$ interval. The 
frequency to be analysed in this paper are measured during a year long period from April 2005 to March 2006. This equals to over 1.5 billion data points in total, with a very small portion that are missing due to equipment failures etc. The amount of missing data is so small that no statistically significant impact will be caused to the final results.

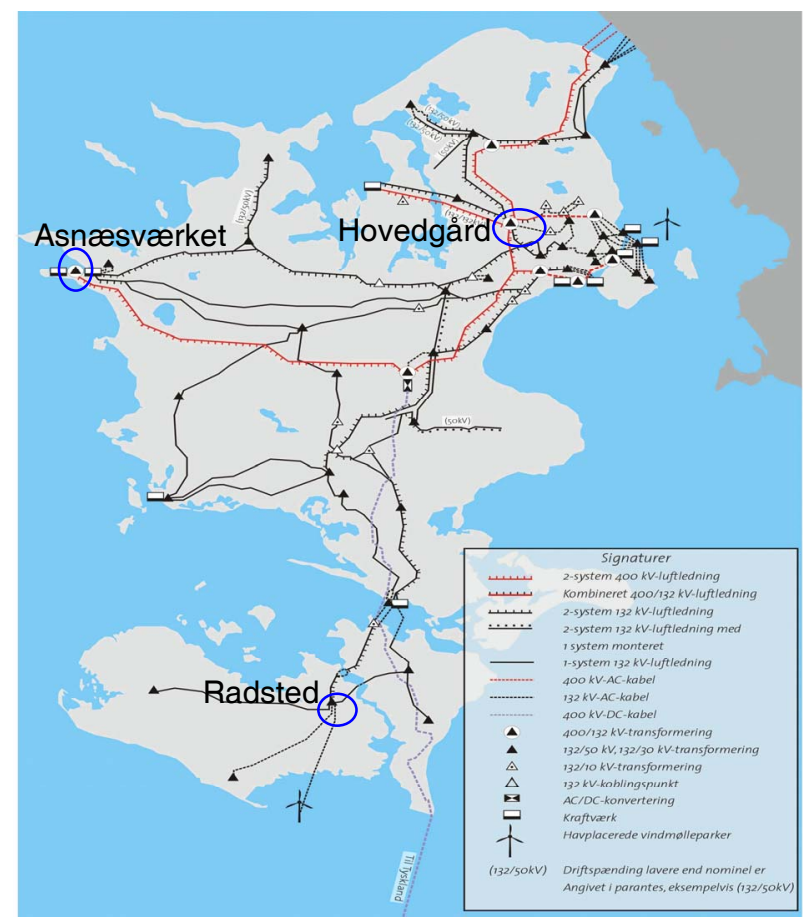

Fig.1. Installation of PMUs inside Eastern Danish System

\section{B. PMUs data acquisition system}

Measurement data acquired by the PMU is compressed and stored locally at each PMU on a built in hard drive. The data is transferred from the PMUs over the internet to CET's PMU-server once a month, where the original data is stored as well as redundant data is calculated for quick viewing of longer time periods. Once on the server the data can be viewed using a web interface on clients with access to the server and the data can be extracted from the server's database for further use.

The PMU's measure voltage and current phasors, along with the frequency and the frequency's rate of change, the detail of the data offers many new possibilities in the use of the data, such as online stability assessment, fault detection, system monitoring, advanced protection schemes and offline analysis of events. Possible applications of this are an early warning instability prediction, offline model verification and frequency analysis.

The high time resolution of the PMU data can provide very detailed information of measured physical quantities. However this also creates a big challenge for data processing works such as raw data extraction and following analyses. In our frequency analyses, the amount of data from PMU measurement is quite huge i.e. $2.93 \mathrm{G}$ bytes for the frequency alone in binary format. We have utilized the SAS software and high performance computing facility at DTU, with over 100 high performance CPUs and Gbytes of memory [6], for data processing.

\section{NORDIC SySTEM FREQUENCY ANALYSIS}

\section{A. Frequency quality evaluation}

The histogram (and the fitted normal distribution) of the frequency data from PMUs has been analysed and presented in Fig 2. As expected, the distribution of frequency is found close to a normal distribution with a mean value of $50.00 \mathrm{~Hz}$ and a reasonable standard deviation of $0.038 \mathrm{~Hz}$. It is also shown that the total number of data points used is over 1.5 billion, with missing observations of 4074.

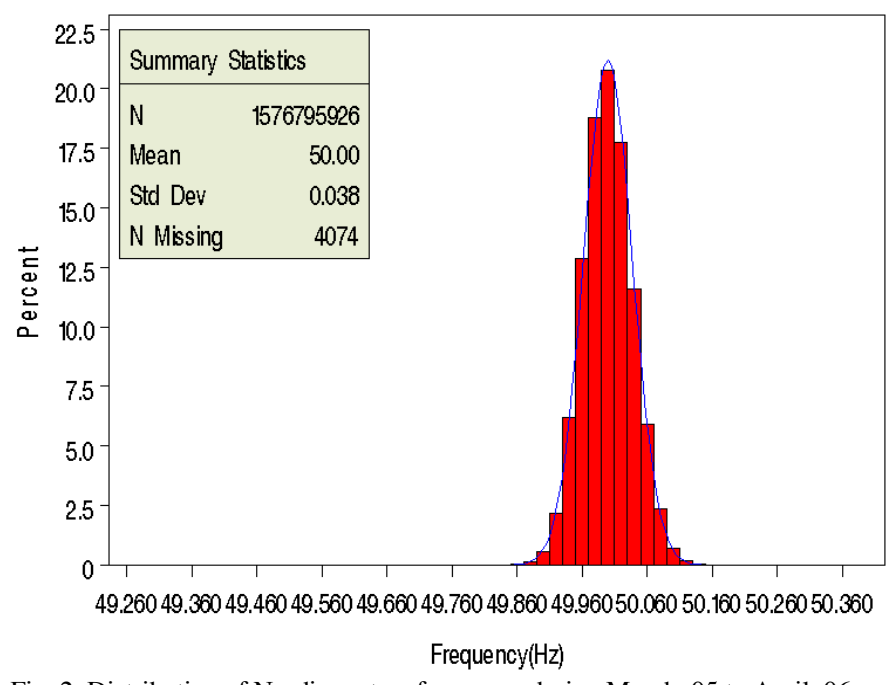

Fig. 2. Distribution of Nordic system frequency during March, 05 to April, 06

TABLE I STATISTICS OF LOW FREQUENCY EVENTS IN PMU DATA

\begin{tabular}{|c|c|c|c|c|}
\hline $\begin{array}{c}\text { Frequency } \\
<\mathrm{XX} \mathrm{Hz}\end{array}$ & $\begin{array}{c}\text { No of } \\
\text { events }\end{array}$ & $\begin{array}{c}\text { Mean duration } \\
\text { of events (s) }\end{array}$ & $\begin{array}{c}\text { Std duration } \\
\text { of event (s) }\end{array}$ & $\begin{array}{c}\text { Sum of } \\
\text { duration (s) }\end{array}$ \\
\hline 49.90 & 123889 & 0.8 & 6.5 & 98709.0 \\
\hline 49.85 & 2850 & 0.9 & 9.7 & 2533.9 \\
\hline 49.80 & 266 & 1.5 & 13.2 & 390.0 \\
\hline 49.75 & 42 & 4.6 & 13.9 & 191.5 \\
\hline 49.70 & 6 & 5.8 & 6.2 & 35.1 \\
\hline
\end{tabular}

The distribution of the frequency data can only suggest that the overall frequency quality of Nordic system is generally satisfactory during the measurement period. There are actually events or durations of low or high frequency, due to system events like generation outages etc at certain time. An event of low or high frequency refers to a sequence of observations with frequency lower or higher than certain values, e.g. $49.90 \mathrm{~Hz}$ for a low frequency event. Table I summarizes the statistics of observed low frequency durations in the PMU data for events of frequency lower than 49.90 to $49.70 \mathrm{~Hz}$. The number of low frequency events drops significantly from 123889 to 6 for frequency below 49.90 to $49.70 \mathrm{~Hz}$, respectively. For the critical frequency of $49.90 \mathrm{~Hz}$ which is the triggering frequency for disturbance reserves in the Nordic system, the mean and standard deviations of the event durations are 0.8 and 6.5 seconds respectively. This suggests that these low frequency events are usually short in durations and the system is able to recover when they happened. More importantly, it is found that total period of frequency lower $49.90 \mathrm{~Hz}$ is 98709 seconds, i.e. about 1645 minutes. The length here is actually longer than the operation target of the Nordic system, i.e. about 1200 minutes per year [3], indicating an unsatisfactory frequency quality. It is also 
observed that the duration mean and standard deviation of low frequency events both increase as frequency drops from 49.90 to $49.75 \mathrm{~Hz}$, e.g. $4.6 \mathrm{~s}$ and $13.9 \mathrm{~s}$ for durations below $49.75 \mathrm{~Hz}$.

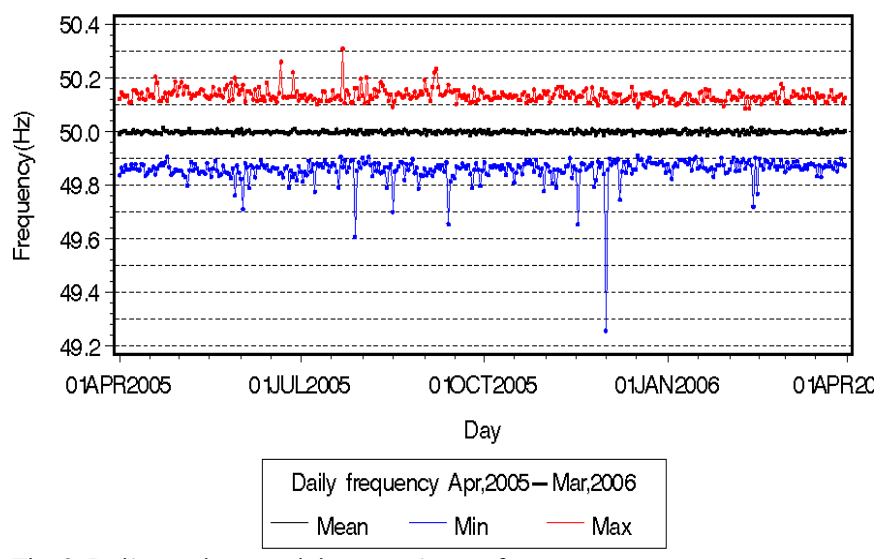

Fig. 3. Daily maximum, minimum and mean frequency

Fig 3 presents the daily maximum, minimum and mean frequency duration the observation period, where the lowest frequency observation of $49.257 \mathrm{~Hz}$ is identified on 01 , December, 2005. This suggests a serious system event on that day. Therefore, the frequency data of that day has been examined, and the period of the lowest frequency event has been identified and plotted out in Fig. 4.

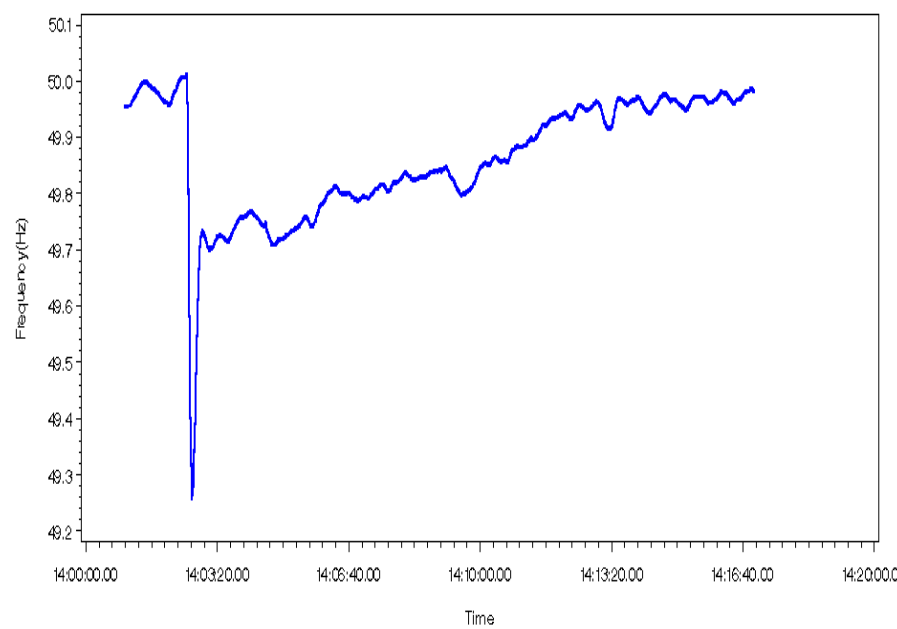

Fig. 4. Time plot of a recorded low frequency event in PMU data with the lowest observation $49.257 \mathrm{~Hz}$ on $01 \mathrm{Dec}, 2005$ (GMT time)

Many kinds of power system accidents can cause a low frequency event like in Fig. 3. In order to find the reason for the recorded worst event, the information in the Urgent Market Message (UMM) system of the Nordic has been checked [6]. The UMM is an information system for the Nordic electricity market NordPool, where information about system operations are published form time to time and shared by the market participants [7]. It turned out that on 01, Dec 2005, a failure in Porjus switchyard led to disconnection of several large hydro power plants in northern Sweden as well as separation between Sweden and Norway in the north. The grid in Norway is separated as well in north-southern direction. The event started from 14:02(GMT time) and lasted for about 40 minutes.

\section{B. Correlation between low frequency probability and observation time}

The frequency quality for the period of the measurement has been evaluated. Though the overall quality is acceptable, the total length of low frequency $(<49.90 \mathrm{~Hz})$ period is over the operation target. Several reasons could contribute to this result. First of all, it could be due to the serious system events, e.g. the event in Fig 4, which have appeared during the measurement period. Other reasons underlying need to be found by further analyses of the highresolution PMU data.

Another possible impacting factor for frequency quality ${ }_{6}$ one can think of is the introduction of the electricity market into system operation. This can be understood as the NordPool dispatches the generation on an hourly basis according to the competition results which may not be optimal for frequency control compared to the centralized dispatching in the past [8]. In order to verify this conjecture, the correlation analysis between the low freuqnecy and observation time has been conducted using the PMU data. Fig 5 shows the relation between the low frequency probability $(<49.90 \mathrm{~Hz})$ and the minute in hour, where high probabilities of low frequency are clearly observed at the beginning and end of an hour. This result supports our conjecture about the impact of NordPool's hourly transitions on system frequency quality. In addition, we have found similar low frequency distribution for the UCTE (the power system of mainland Europe) system though with much better quality- less probability of under frequency, which again confirms that hourly market does have impacts on system frequency.

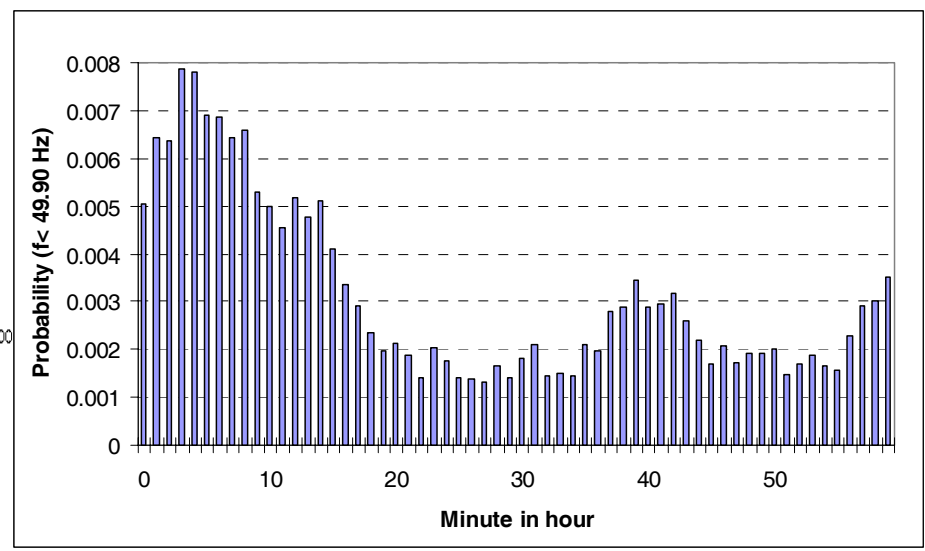

Fig. 5. Probability of frequencies under $49.9 \mathrm{~Hz}$ within the minute of the hour

The correlation between low frequency probability and observation time have been further probed. Fig 6 presents contour plot of the correlations between low frequency probability, minute in hour and hour in day. Besides the high probabilities in the beginning and end of an hour, the plot also suggests low frequency is more likely to happy late in an hour and early of a day, i.e. at about the $40^{\text {th }}$ minute in an hour and 4am in a day. One possibly explanation to this observation is that early of a day, the system demand is at relatively low level. Accordingly, the system inertia and damping are relatively low, and the system has high probability to oscillate if disturbances occur. More investigations need to be done in the future to clarify this. 


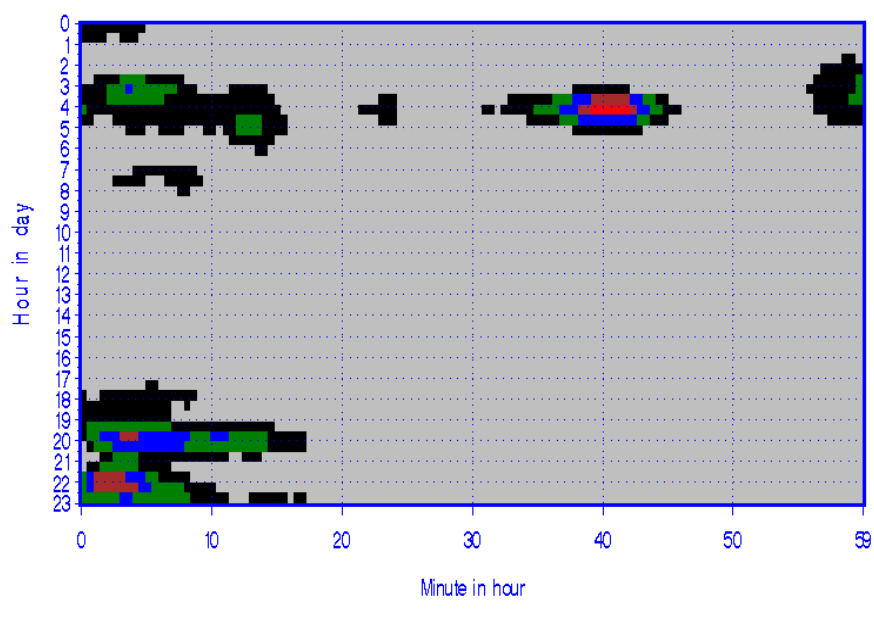

Probability of low trequency $(1<49.90 \mathrm{~Hz})$

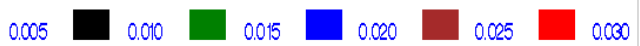

Fig. 6. Contour plot of correlation between low frequency probability, minute in hour and hour in day

\section{Discussion of frequency control in the future}

In a practical power system, frequency control or the power balancing control usually involves a hierarchical structure. Take the Nordic system as an example, the first hierarchy is realized through the electricity market operation, i.e. NordPool, where generation is dispatched to match the load. On top of the market operation, the system operators need to procure several kinds of active power reserves to ensure reliable control of power balance. These reveres in the Nordic include the following [2], and their dynamics are plotted in Fig 7,

- Frequency controlled normal reserve, which is to be linearly and completely activated between and at frequency $=49.90 / 50.10 \mathrm{~Hz}$, and within 2minutes

- Frequency controlled disturbance reserve, which is to be linearly activated when frequency dorps between 49.50 and $49.90 \mathrm{~Hz}$. 50\% of such reserve should be activated within 5 seconds, and $100 \%$ should be activated within 30 s

- Fast and slow active disturbance reserves are to be activated in 15 minutes or so

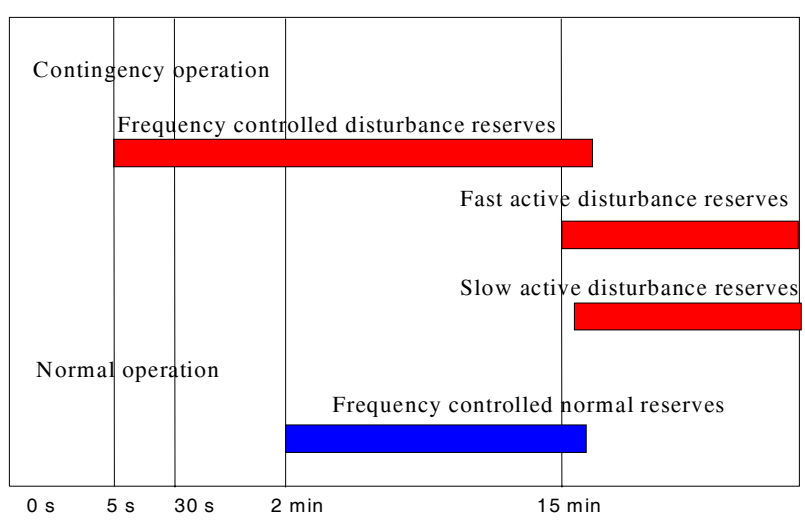

Fig. 7. Real power reserves dynamics in Nordic system

In the past, the hierarchical approach of frequency control has long been proved sufficient. The reserves in this approach are mainly from generation side, e.g. automatic reserve from primary and secondary control of generators, and manual regulation of generators and HVDC flows. With the appearance of electricity markets and increased use of fluctuating renewable energy, will the well established frequency control scheme still be sufficient is a critical question to be investigated.

The frequency analysis in this paper provides a good starting point for such analysis, where the frequency quality is found deviating from the suggested operation target, i.e. the total duration of under frequency $(<49.90 \mathrm{~Hz})$ is over the expectation. In addition, the electricity market is clearly identified as a major impacting factor for the frequency quality, while other reasons like penetration of renewable energy should also be considered.

For the analysed period, the penetration of renewable energy into the Nordic electric power system is still moderate, e.g. the wind generation occupies only $\mathbf{2 \%}$ of total energy consumption in year 2005 [9], and their impacts to frequency quality are therefore limited. It is foreseen that the penetration of distributed and renewable energy into the Nordic will be continuously increasing, so as their impacts. E.g. the new Danish Energy Policy suggests a high ambition of $50 \%$ penetration of wind energy into Danish power system by 2025 . Consequently, the frequency control in the future is expected to be more challenging for such system [10].

To enhance frequency control in future power system, new measures and possibilities should be considered. The demand side technology is a possible solution with much potential. Several good reasons exist for exploring demand side including, well-distributed, pollution free, low costs resources with large volume and fast response [11]. It has been proved that the demand can provide frequency control services of all time dimensions, from slow to fast, and participate into corresponding markets in the Nordic system [12]. One of the demand side technologies for fast reserve under our investigation is demand as frequency controlled reserve (DFR), of which promising results have been achieved from theoretical study, and a practical demonstration project is under planning [13]. Other technologies to be investigated in the future include, but not limited to,

- Frequency control for renewable energy recourses, e.g. frequency control of wind turbines [14]

- Virtually integrated distributed generations (DGs) for effective energy and ancillary services provision [15]

- Electric vehicles and their integration with the Grid [16]

- Efficient electricity management for future households with DGs and smart consumer appliances etc. [17]

- New energy storage technologies, such as fly wheel etc and rechargeable battery etc [18].

Furthermore, the coordination and interplay between the new and existing technologies for frequency control should also be investigated to ensure their seamless integration. Such an investigation should be guided towards a new control architecture for the future power system. [19, 20]. 


\section{CONCLUSION}

The frequency quality of the Nordic electric power system has been evaluated using high time resolution data from PMUs. The results demonstrate that during the measurement period, the frequency quality of the Nordic system is generally satisfactory though with exceptions due to system events and etc. The total duration of frequency lower than $49.90 \mathrm{~Hz}$ is found over the operation target. By studying the correlation between the low frequency probability and the observation time, the electricity market is identified as the one of the major impacting factor for low frequency observations. Based on the frequency analysis, discussions of frequency control for future power system has been carried out. New control measures and possibilities have been suggested to be investigated in our future scope.

\section{REFERENCES}

[1] P. Kundur, "Power System Stability and Control", McGraw-Hill, 1994

[2] Nordel, "Nordic Grid Code", 2004.

[3] B. Bakken, and A. Petterteig, "Reserve requirements and security of supply", Sintef. Capacity shortage seminar, Gardemoen, April 2005

[4] A. H. Nielsen, K. O. H. Pedersen, P. Jørgensen, J. Havsager, S. K. Olsen, J. Rasmussen, "Phasor Measurement Units in the Eastern Danish power system”, CIGRE Conference 2006, Paris, France, pp 1-5, Conseil International des Grands Réseaux Électriques, 2006

[5] O. Samuelsson, M. Hemmingsson, A. H. Nielsen, K. O. H. Pedersen, J. Rasmussen, "Monitoring of power system events at transmission and distribution level", IEEE Transactions on Power Systems, vol 21(2), pp 1007-1008, 2006

[6] High Performance Computing Systems at Technical University of Denmark, online at www.gbar.dtu.dk

[7] UMM, online at http://www.nordpoolspot.com/umm/

[8] The Nordic Model, online http://www.nordpoolspot.com/PowerMaket/

[9] Nordel annual report 2005

[10] Danish Ministry of Transport and Energy, "Energistrategi 2025”, 2007.

[11] Z. Xu, J. Østergaard, M. Togeby, and C. Marcus-Møller, "Design and Modeling of Thermostatically Controlled Loads as Frequency Controlled Reserve", Proc. of 2007 IEEE PES General Meeting.

[12] F. M. Andersen, S. G. Jensen, H. V. Larsen, P. Meibom, H. Ravn, K. Skytte, M. Togeby, "Demand repsone in Denmark:”, Ris $\varnothing$ National Laboratory Report, Risø-R-1565(EN), 2006

[13] CET project-Electricity demand as frequency controlled reserve, online at http://www.dtu.dk/centre/cet/English/research/projects/06-ea.aspx

[14] CET project Coordinated frequency control of wind turbines in power systems with high wind power penetration, online at http://www.dtu.dk/centre/cet/English/research/projects/13_Coordinated_ frequency_control.aspx

[15] CET project Generic Virtual Power Plant for Optimized micro CHP Operation and Integration, online at http://www.oersted.dtu.dk/English/research/eltek/res_projects/0610/sy.aspx

[16] CET research proposal, "Vehicle to Grid (V2G)", 2007

[17] CET research proposal, "Efficient Electric Energy Management for Smart House", 2007

[18] K. C. Divya and J. Østergaard " Battery Energy Storage Technology for power systems-An overview", Submitted to Electric Power Systems Research.

[19] EU SmartGrids initiative, http://www.smartgrids.eu/

[20] CET research project NextGen - Control Architecture for Intentional Islanding Operation in Future Distribution Network with High Penetration of Distributed Generation, online at http://www.oersted.dtu.dk/English/research/eltek/res_projects/0610/cy.aspx 